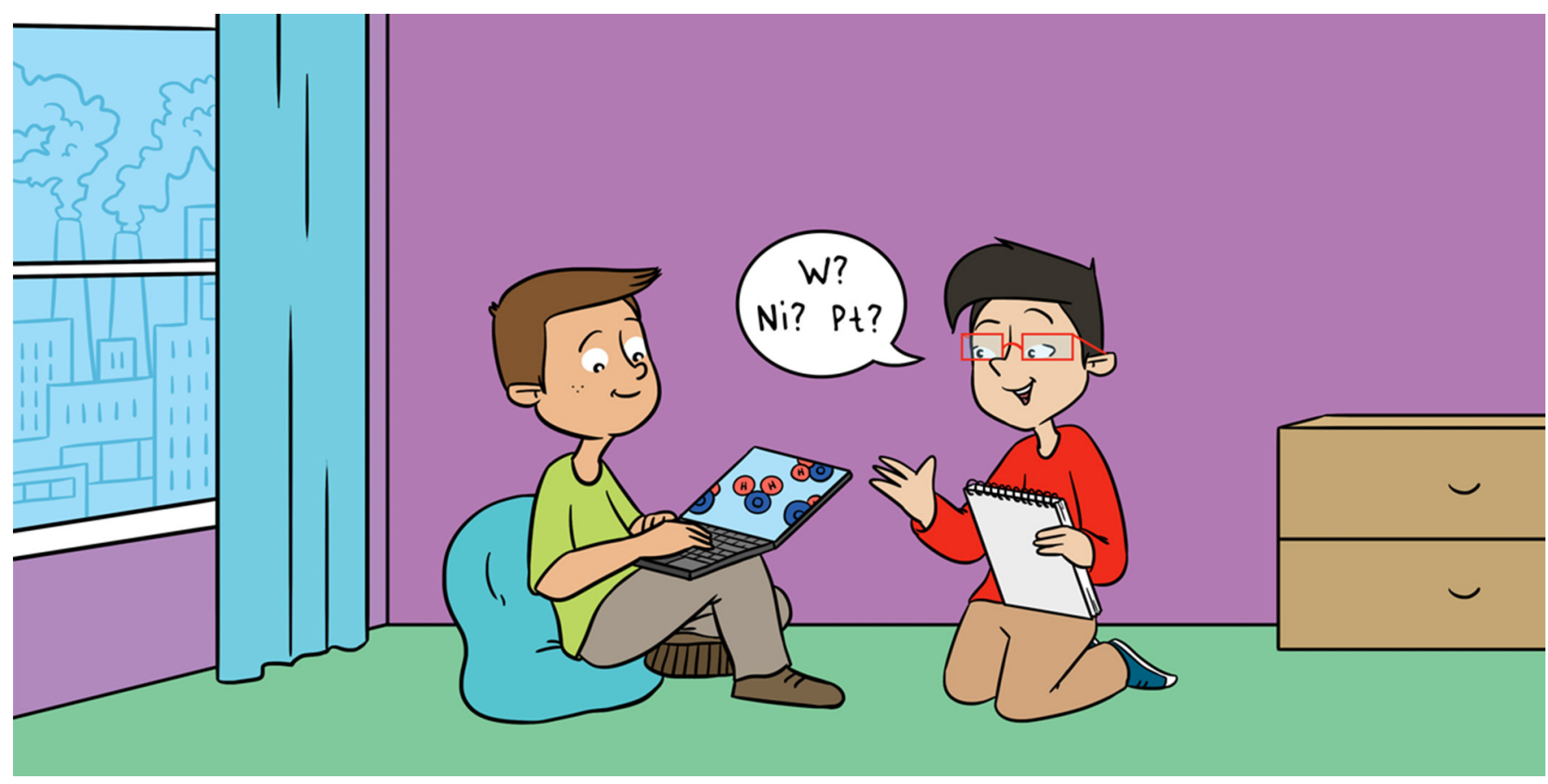

\title{
USING COMPUTERS TO DISCOVER MATERIALS THAT GENERATE NON-POLLUTING FUELS
}

\section{Santu Biswas and Maytal Caspary Toroker*}

Department of Materials Science and Engineering, The Nancy and Stephen Grand Technion Energy Program, Technion-Israel Institute of Technology, Haifa, Israel

YOUNG REVIEWERS:

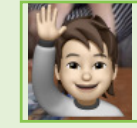

YOTAM AGE: 11
Non-polluting fuels, such as hydrogen, are widely considered to be a promising way to decrease the environmental problems caused by the burning of fossil fuels. Finding materials that can help us to generate these "clean" fuels is a difficult and time-consuming process. Computer simulation technology is the most important tool in this area, because it helps scientists to understand existing materials and can also help them to design new types of materials. In this article, we explain how certain materials can help us to produce hydrogen, a clean fuel, from water, and we also describe how computer simulation technology can offer a route for the discovery of new efficient materials.

\section{WHAT IS A CLEAN ENERGY SOURCE?}

Energy is needed for many of the activities in our everyday lives. We need energy for watching television, washing clothes, cooking, lighting the home, transportation, heating, cooling, just to name a 
Figure 1

Burning fossil fuels to create energy causes the release of several gasses, including carbon dioxide $\left(\mathrm{CO}_{2}\right)$, which cause environmental pollution and contribute to global warming.

\section{FOSSIL FUELS}

Fuels formed by natural processes, such as decomposition of ancient plants and animals over millions of years that can be used as a source of energy.

\section{GLOBAL WARMING}

The increase in Earth's average surface temperature over a long period of time.

\section{CLEAN ENERGY}

Energy that is produced in a way that does not pollute

the environment.

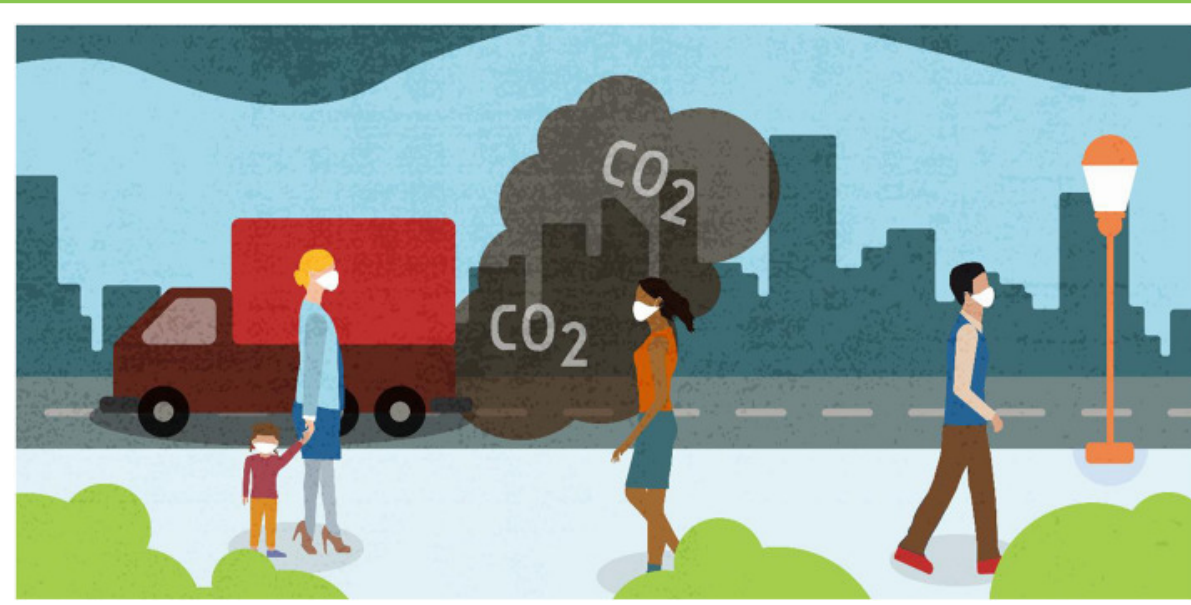

Figure 1

few. Global energy consumption is increasing as a result of population growth. However, the world is not yet short of energy, as most of our energy requirements are met by burning fossil fuels. Fossil fuels include coal, oil, and natural gas. Unfortunately, fossil fuel sources are not environmentally friendly. Burning of fossil fuels generates pollutant gases, such as carbon dioxide $\left(\mathrm{CO}_{2}\right)$, that pollute the environment (Figure 1). Perhaps the most well-known effect of burning fossil fuels is global warming, which is mainly caused by $\mathrm{CO}_{2} \cdot \mathrm{CO}_{2}$ traps solar heat within the atmosphere, which increases the temperature on earth every year [1]. We know that human beings and other animals breathe out $\mathrm{CO}_{2}$, and plants absorb $\mathrm{CO}_{2}$. So, plants can naturally remove a certain amount of $\mathrm{CO}_{2}$ from the atmosphere. But now there is an excessive volume of $\mathrm{CO}_{2}$ in the atmosphere, and plants are no longer able to deal with that without help.

We clearly need an energy solution that does not generate the pollution caused by $\mathrm{CO}_{2}$ and other gas emissions. The solution could be clean energy! Clean energy can be defined as an energy source that is environmentally friendly, more sustainable, and produced from sources, such as solar energy or wind power. Solar energy converts light from the sun into energy for the generation of electricity. Wind power takes advantage of wind motion to generate electricity. Solar and wind power are considered environmentally friendly because they emit no toxic gases into the environment. It is easy to see the environmental advantages of using clean energy, but we must also be aware of the disadvantages. In the case of solar power, it is currently expensive, and sunlight is not available at night. In the case of wind power, no energy is generated when the wind is not blowing, and harnessing wind power requires a lot of land. Therefore, it is important that we continue to search for alternative clean energy resources that can fulfill the energy demands of our everyday lives. 
Figure 2

Water splitting is a way to create hydrogen fuel by breaking water down into its

components, hydrogen $\left(\mathrm{H}_{2}\right)$ and oxygen $(\mathrm{O})$. Certain materials called catalysts (yellow and red blocks) can help the splitting reaction happen faster and reduce the amount of energy needed for the reaction.

\section{WATER SPLITTING}

The conversion of water into its chemical components, oxygen, and hydrogen. The hydrogen can be used as fuel.

\section{CATALYST}

A material that speeds up a chemical reaction The process of speeding up the reaction is called catalysis.

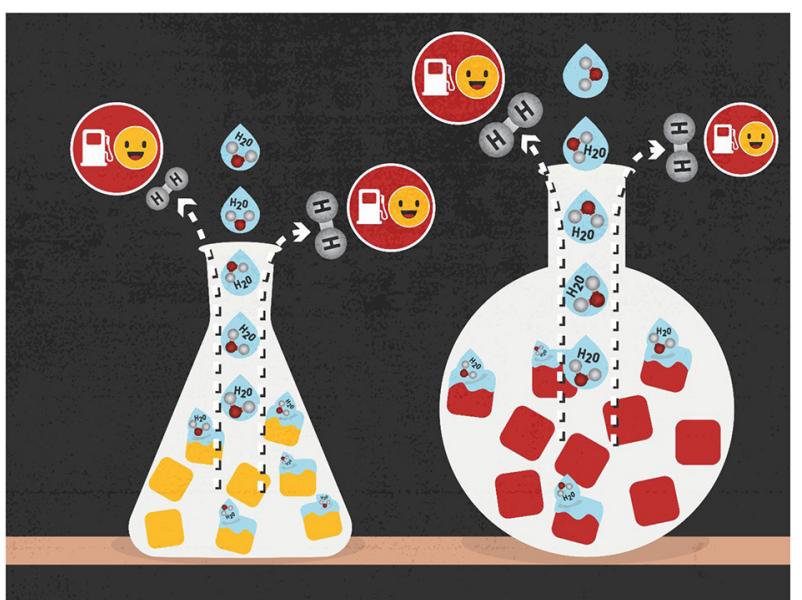

Figure 2

\section{HYDROGEN: A SOURCE OF CLEAN ENERGY}

Efforts have been made to develop new, environmentally friendly clean energy sources, such as hydrogen fuel produced from water. Hydrogen is considered an ideal fuel to supply the world's energy needs for the future. Hydrogen is a non-polluting fuel that can be used for transportation, heating, and electricity. Furthermore, hydrogen is considered "high efficiency" because it contains the highest energy content by weight of any known fuel.

Hydrogen can be produced from water. The chemical formula of water, $\mathrm{H}_{2} \mathrm{O}$, means that each water molecule contains two hydrogens $\left(\mathrm{H}_{2}\right)$ and one oxygen $(\mathrm{O})$. Getting hydrogen from water, a process known as water splitting, is a chemical reaction in which water is broken into its oxygen and hydrogen components, if enough energy is supplied. The energy for water splitting can come from electricity, heat, or light, with the aid of special materials called catalysts. Catalysts are generally small chemicals that can do a great job of reducing the amount of energy needed for a reaction to happen, such as the splitting of water.

\section{HOW CAN CATALYSTS HELP US GET HYDROGEN FROM WATER?}

How can catalyst materials help with splitting water? These materials first attach a water molecule to their surface, by forming a chemical bond between the oxygen atom of water and the surface atoms of the catalyst. The water molecule is distorted because of this bonding, such that it more easily breaks down into oxygen and hydrogen (Figure 2). This is how the material acts as a catalyst-it assists in splitting the water by speeding up this reaction. With the helping hand of a catalyst material, molecules that might take years to react can do so in seconds. 
The key to choosing an efficient catalyst material lies in the amount of energy needed to initially attach a water molecule to the material, as well as the amount of energy required to split the water molecule. The less energy needed for attaching and splitting, the better the catalyst. In the past decade, many materials have been investigated as catalysts for the splitting of water [2]. One of the first materials demonstrated to catalyze the splitting of water to produce hydrogen was titanium dioxide $\left(\mathrm{TiO}_{2}\right)$. After that, many scientists around the globe devoted their time to create and characterize different types of materials for catalyzing water splitting. But the development of new and superior materials is extremely complicated and difficult to understand. When researchers try to build a new material, multiple chemical elements can be used in various combinations. So, there are endless possibilities, and this research is very time consuming. Also, researchers may spend a lot of time developing a new catalyst only to find that the material is not stable or is unable to split water! So, we need to find a more efficient way to identify potential catalysts.

\section{THE IMPORTANCE OF COMPUTER SIMULATION}

The most important tool to help scientists better understand how to design new materials is the computer. Computer programs contain groups of instructions that are typically used to solve a problem, or to make larger problems smaller and easier to solve. During the past few

\section{SIMULATION}

A computer technique that uses rules from mathematics and sciences to mimic a real-life situation. years, computer simulation technology has played an important role in materials science research. With the help of computer simulation techniques, we can search for new materials that are able to catalyze water splitting.

Computers can be used to simulate the process of water splitting with a potential new catalyst, to test whether the catalyst material is efficient (Figure 3). Computer simulations can show researchers in detail what happens on the surface of the catalyst material, revealing the interactions between the catalyst material and the water molecules. Computers can calculate the binding strength and compatibility of water molecules to a potential catalyst material. Researchers first provide the computer with information about the composition of the potential catalyst material. The computer considers all possible locations where the water molecules might attach to the material's surface. The computer then calculates the sum of all chemical connections between the water and the material, and then predicts the most likely location where water will bind to the material's surface. The computer provides researchers with a lot of data on the geometry of the water molecule as it attaches to the catalyst's surface, as well as the geometry of the water when it is split to form hydrogen. The computer can also calculate the energy needed for water splitting.

A good catalyst is one that makes the water-splitting process faster and more efficient. An efficient catalyst must bind water molecules 
Figure 3

Computer simulation technology can help researchers more easily identify and develop new catalyst materials.

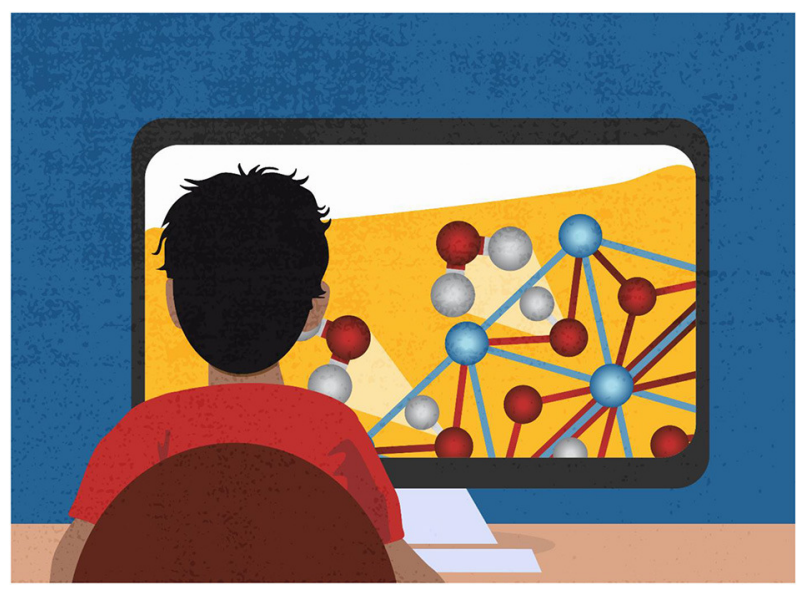

Figure 3

strongly enough for the molecules to attach, but not so strongly that hydrogen and oxygen stay stuck after the water is split. For example, silver is not a good catalyst because the interaction between water molecules and silver is weak. On the other hand, tungsten is not a good catalyst either, because water attaches too strongly. Platinum and nickel make good catalysts because they attach to water strongly enough to hold the water molecules close and split the water. Other types of materials that are less expensive and more stable have been reported over the past few decades. Iron-, cobalt-, and nickel-based oxide materials, as well as materials containing sulfide, selenide, and phosphide have all been shown to be good materials for producing hydrogen from water [3].

Among the various materials recently proposed as a good catalyst for the splitting of water, nickel-iron oxyhydroxide (NiFeOOH) is one of the most efficient. Recently our group, which specializes in characterizing materials with computers [4], found out why NiFeOOH can split water so efficiently: it attaches water to areas of the material that contain iron [5]. The computer simulation showed us that iron is an especially important part of the material since it allows water to split without the need for much energy.

\section{SUMMARY}

Water splitting is a promising approach for producing clean hydrogen fuel that will not pollute the environment or contribute to global warming. Splitting water molecules in the presence of a catalyst material is a useful way to obtain hydrogen; but developing and testing these catalysts is a long and difficult process. Computers can help! The beauty of computer simulation is that it is much faster than physically testing all the potential catalyst materials. Using computers, researchers can monitor the process of the water-splitting reaction 
to discover which catalyst material is most efficient. Using computer simulation technology, we can design more materials that can be used for the generation of clean energy sources that are not harmful to the environment. Clean energy will eventually reduce the impact of global warming and benefit all of society.

\section{ACKNOWLEDGMENTS}

This research has received funding from the Nancy and Stephen Grand Technion Energy Program (GTEP) and The Israel Science Foundation (Grant No. 880/20).

\section{REFERENCES}

1. Mardani, A., Streimikiene, D., Cavallaro, F., Loganathan, N., and Khoshnoudi, M. 2019. Carbon dioxide $\left(\mathrm{CO}_{2}\right)$ emissions and economic growth: a systematic review of two decades of research from 1995 to 2017. Sci. Total Environ. 649:31-49. doi: 10.1016/j.scitotenv.2018.08.229

2. Chen, S., Thind, S. S., and Chen, A. 2016. Nanostructured materials for water splitting-state of the art and future needs: a mini-review. Electrochem. Commun. 63:10-7. doi: 10.1016/j.elecom.2015.12.003

3. Anantharaj, S., Ede, S. R., Sakthikumar, K., Karthick, K., Mishra, S., and Kundu, S. 2016. Recent trends and perspectives in electrochemical water splitting with an emphasis on sulfide, selenide, and phosphide catalysts of $\mathrm{Fe}, \mathrm{Co}$, and $\mathrm{Ni}$ : a review. ACS Catal. 6:8069-97. doi: 10.1021/acscatal.6b02479

4. Snir, N., Yatom, N., and Caspary Toroker, M. 2019. Progress in understanding hematite electrochemistry through computational modeling. Comput. Mater. Sci. 160:411-9. doi: 10.1016/j.commatsci.2019.01.001

5. Fidelsky, V., and Toroker, M. 2017. The secret behind the success of doping nickel oxyhydroxide with iron. Phys. Chem. Chem. Phys. 19:7491-7. doi: 10.1039/C6CP08590C

SUBMITTED: 01 January 2021; ACCEPTED: 22 April 2021; PUBLISHED ONLINE: 10 June 2021.

EDITED BY: Idan Segev, Hebrew University of Jerusalem, Israel

CITATION: Biswas S and Caspary Toroker M (2021) Using Computers to Discover Materials That Generate Non-polluting Fuels. Front. Young Minds 9:648750. doi: 10. 3389/frym.2021.648750

CONFLICT OF INTEREST: The authors declare that the research was conducted in the absence of any commercial or financial relationships that could be construed as a potential conflict of interest.

COPYRIGHT (C) 2021 Biswas and Caspary Toroker. This is an open-access article distributed under the terms of the Creative Commons Attribution License (CC BY). The use, distribution or reproduction in other forums is permitted, provided the 

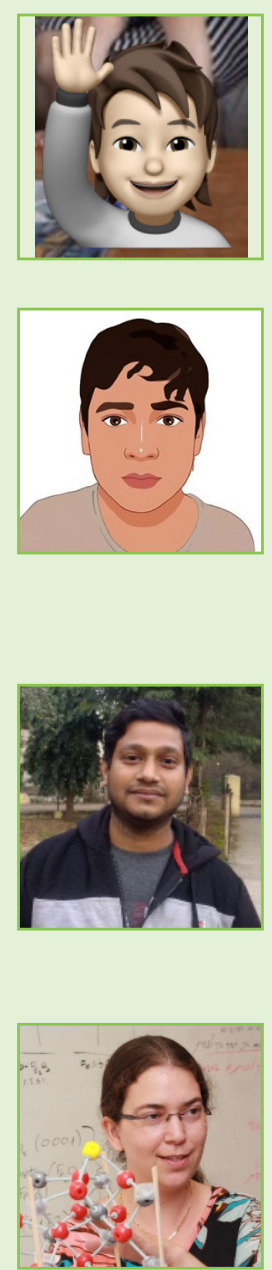

original author(s) and the copyright owner(s) are credited and that the original publication in this journal is cited, in accordance with accepted academic practice. No use, distribution or reproduction is permitted which does not comply with these terms.

\section{YOUNG REVIEWERS}

\section{ROY, AGE: 11}

I am in sixth grade, love chess, reading, and the musical Hamilton. I also play tennis.

\section{YOTAM, AGE: 11}

My name is Yotam, I am in the sixth grade in the gifted and mathematics program at Bar Ilan. I like playing computer games, cycling, and Pokemon. My favorite fields of study are science and math. I am the eldest of three brothers.

\section{AUTHORS}

\section{SANTU BISWAS}

I am a post-doctoral student at the Technion-Israel institute of Technology. Currently my research work is focused on $\mathrm{CO}_{2}$ electrolysis with different perovskite materials, water splitting with metal oxide clusters, and metal-organic framework catalysis. I received my doctorate degree from Visva-Bharati University, India. I love to play cricket and it is very important for me to spend time with my family and friends.

\section{MAYTAL CASPARY TOROKER}

I am a professor in the Faculty of Materials Science and Engineering at the Technion. The research in my lab deals with the theoretical calculation of the properties of materials, especially the properties of electronic conduction through materials. We use computer tools based on algorithms from quantum physics to understand how materials behave at the atomic level. With this understanding, it is possible to engineer new materials that can be used to build electronic devices like batteries, transistors, and solar cells. *maytalc@technion.ac.il 